\title{
EDITORIAL
}

\section{Decision aids for breast cancer chemoprevention}

\author{
llona Juraskova ${ }^{*}$ and Carissa Bonner
}

\begin{abstract}
The article by Korfage and colleagues in this issue of Breast Cancer Research highlights the importance of enabling women to make informed choices about breast cancer chemoprevention. Decision aids have the potential to improve knowledge and decisionmaking in this context, but they do not guarantee increased uptake of chemoprevention amongst highrisk women if this option is inconsistent with women's values. Important avenues for further research in this area include evaluating: decision aids with explicit values clarification exercises and with comparison between chemoprevention and nonpharmacological options to reduce breast cancer risk, the influence of mediating factors such as anxiety and risk perception, and the role of clinicians and family members in decision-making.
\end{abstract}

The article by Korfage and colleagues in this issue of Breast Cancer Research investigates the efficacy of an online decision aid for improving informed decisionmaking about breast cancer chemoprevention amongst women with increased risk of developing breast cancer [1]. This study combines two areas of high interest in the research literature: the potential of chemoprevention to reduce the burden of cancer [2], and the use of decision aids to improve patient knowledge and decisionmaking in the prevention setting $[3,4]$.

The efficacy of chemoprevention for breast cancer prevention is well established, and recently updated clinical guidelines recommend discussing several chemoprevention options with women at increased breast cancer risk: tamoxifen, raloxifene and exemestane [2]. However, a review of breast cancer chemoprevention decision-making indicates that interest amongst high-risk women is low: $25 \%$ on intention measures and $15 \%$ for actual uptake, reflecting a perception that the benefits do not outweigh

\footnotetext{
*Correspondence: ilona.juraskova@sydney.edu.au

Centre for Medical Psychology and Evidence-based Decision-making, School of Psychology, Brennan MacCallum (A18), The University of Sydney, Sydney, NSW 2006, Australia
}

the harms for many women [5]. This sensitivity to individual preferences makes it an ideal setting for decision support interventions. Decision aids are nondirective, unbiased tools that provide patients with evidence-based information about their medical options and expected outcomes, in clear, verbal and visual formats [4]. They help patients to understand their available options, and weigh up the pros and cons of each option in light of their own values, in order to make an informed decision. Systematic reviews have shown that decision aids improve knowledge of medical options and outcomes, enable more realistic expectations, reduce decisional conflict, and increase active participation in screening and treatment decisions, including the cancer setting $[3,4]$.

The majority of studies on decision-making in the breast cancer chemoprevention context have been based on hypothetical scenarios, which may not predict actual uptake, and there is a need for more research on the quality and underlying mechanisms of decision-making [5]. In the article that accompanies this editorial, Korfage and colleagues contribute new evidence to this field by examining both intention and uptake decision 3 months later, in relation to sufficient knowledge and consistent attitudes towards chemoprevention [1]. They demonstrate a novel way to measure whether the decision was informed or not, based on the Multidimensional Measure of Informed Choice [6]. Deciding to take chemoprevention with a positive attitude, deciding against chemoprevention with a negative attitude, or remaining undecided with a neutral attitude towards chemoprevention were all considered informed decisions, if women demonstrated sufficient knowledge regarding potential benefits and risks.

While further research is needed to establish the validity of this dichotomous outcome in comparison with more established measures, the authors' conceptualisation of informed choice highlights an important distinction between the prevention and treatment setting. That is, remaining undecided may be considered rational when there is sufficient knowledge but ambivalent attitudes towards a preventive option, since this context is not as time sensitive as a treatment decision. Korfage and colleagues' results suggest that the decision aid improved informed 
choice at the intention stage but not at 3-month followup, at which point informed choice was low across both intervention and control groups due to decreased knowledge [1]. Analysis of mediating factors in future research may shed more light on the issue of knowledge retention. Two factors suggested by previous research are: breast cancer-related anxiety, which has been shown to motivate intention but also impair the processing of information [7]; and the difference between estimated and perceived risk, which may help to explain why women are ambivalent towards the use of chemoprevention despite evidence of its efficacy in reducing risk [5].

The negative attitudes towards chemoprevention found in this study are common to many other diseases for which medication would be effective [8], and it is important to note that the use of decision aids will not increase uptake of chemoprevention if this option is simply inconsistent with most women's values regarding the relative benefits and harms. Decision aids do have the potential to improve informed choices about breast cancer chemoprevention [3,4], but since $45 \%$ of women who received this decision aid remained undecided after 3 months [1] additional decisional support may be needed in this context. Decision aids with explicit value clarification exercises, designed to help patients clarify how important the potential benefits and harms are to them, have been shown to improve informed choice $[4,9]$. Comparison of chemoprevention with nonpharmacological options to reduce breast cancer risk, including surgical and lifestyle options, could also be an important addition to decision aids to help women make a decision based on knowledge of all the available options.

From a broader perspective, women commonly seek information about breast cancer online, in response to regular awareness campaigns [10] and less predictable media coverage of celebrity experiences [11], such as the recent case of Angelina Jolie's preventive double mastectomy to reduce her high risk of breast cancer [12]. Having evidence-based information and decision support tools readily available and promoted in the public domain is therefore important. The online decision aid format demonstrated by Korfage and colleagues also allows the information to be tailored to an individual's known risk factors [1].

Decision aids can also play a role in improving communication with clinicians and family members, who are important sources of both information and values [13] and may have a strong influence on women's choices about chemoprevention $[14,15]$. Indeed, preliminary research indicates that decision aids can have a positive effect on doctor-patient communication [5]. Further research in this area should recognise the need for doctor-patient-family partnership, and mediating factors known to influence decision-making, to help women make fully informed choices about breast cancer chemoprevention.

\section{Competing interests}

The authors declare that they have no competing interests.

Published: 17 September 2013

\section{References}

1. Korfage I, Fuhrel-Forbis A, Ubel P, Zikmund-Fisher B, Greene S, McClure J, Smith D, Hensly Alford S, Fagerlin A: Informed choice about breast cancer prevention: randomized controlled trial of an online decision aid intervention. Breast Cancer Res 2013, 15:R74.

2. Visvanathan K, Hurley P, Bantug E, Brown P, Col NF, Cuzick J, Davidson NE, DeCensi A, Fabian C, Ford L, Garber J, Katapodi M, Kramer B, Morrow M, Parker B, Runowicz C, Vogel VG III, Wade JL, Lippman SM: Use of pharmacologic interventions for breast cancer risk reduction: American Society of Clinical Oncology Clinical Practice Guideline. J Clin Oncol 2013. Epub ahead of print.

3. O'Brien MA, Whelan TJ, Villasis-Keever M, Gafni A, Charles C, Roberts R, Schiff S, Cai W: Are cancer-related decision aids effective? A systematic review and meta-analysis. J Clin Oncol 2009, 27:974-985.

4. Stacey D, Bennett CL, Barry MJ, Col NF, Eden KB, Holmes-Rovner M, Llewellyn-Thomas H, Lyddiatt A, Légaré $F$, Thomson R: Decision aids for people facing health treatment or screening decisions [review]. Cochrane Database Syst Rev 2011, 10, CD001431.

5. Ropka ME, Keim J, Philbrick JT: Patient decisions about breast cancer chemoprevention: a systematic review and meta-analysis. J Clin Oncol 2010, 28:3090-3095.

6. Michie S, Dormandy E, Marteau TA: The multi-dimensional measure of informed choice: a validation study. Patient Educ Couns 2002, 48:87-91.

7. Dillard AJ, Scherer L, Ubel PA, Smith DM, Zikmund-Fisher BJ, McClure JB, Greene S, Stark A, Fagerlin A: Breast cancer anxiety's associations with responses to a chemoprevention decision aid. Soc Sci Med 2013, 77:13-19.

8. Pound P, Britten N, Morgan M, Yardley L, Pope C, Daker-White G, Campbell R: Resisting medicines: a synthesis of qualitative studies of medicine taking. Soc Sci Med 2005, 61:133-155.

9. Feldman-Stewart D, Tong C, Siemens R, Alibhai S, Pickles T, Robinson J, Brundage MD: The impact of explicit values clarification exercises in a patient decision aid emerges after the decision is actually made: evidence from a randomized controlled trial. Med Decis Making 2012, 32:616-626.

10. Glynn RW, Kelly JC, Coffey N, Sweeney KJ, Kerin MJ: The effect of breast cancer awareness month on internet search activity: a comparison with awareness campaigns for lung and prostate cancer. BMC Cancer 2011, 11:442.

11. Metcalfe D, Price C, Powell J: Media coverage and public reaction to a celebrity cancer diagnosis. J Public Health 2011, 33:80-85.

12. My Medical Choice. http://www.nytimes.com/2013/05/14/opinion/mymedical-choice.html? $r=0$.

13. Laidsaar-Powell RC, Butow PN, Bu S, Charles C, Gafni A, Lam WWT, Jansen J, McCaffery KJ, Shepherd HL, Tattersall MH, Juraskova I: Physician-patientcompanion communication and decision-making: a systematic review of triadic medical consultations. Patient Educ Couns 2013, 91:3-13.

14. Razzaboni E, Toss A, Cortesi L, Marchi I, Sebastiani F, De Matteis E, Federico $\mathrm{M}$ : Acceptability and adherence in a chemoprevention trial among women at increased risk for breast cancer attending the Modena Familial Breast and Ovarian Cancer Center (Italy). Breast J 2013, 19:10-21.

15. Mulley AG, Sepucha K: Making good decisions about breast cancer chemoprevention. Ann Intern Med 2002, 137:52-54.

doi:10.1186/bcr3479

Cite this article as: Juraskova and Bonner: Decision aids for breast cancer chemoprevention. Breast Cancer Research 2013 15:106. 